\title{
APLICAÇÃO SISTÊMICA DO MODO DE ANÁLISE DE FALHAS E EFEITOS (FMEA) PARA O DESENVOLVIMENTO DE INDICADORES DE DESEMPENHO DE EMPRESAS DE PEQUENO PORTE ${ }^{1}$
}

\author{
Roselane Biangaman de Matos² e Marcos Milan²
}

\begin{abstract}
RESUMO - O setor florestal brasileiro emprega direta e indiretamente 6,5 milhões de pessoas, e, dessas, 2,5 milhões estão empregadas no subsetor de madeira processada mecanicamente. O parque industrial voltado à produção de madeira serrada dispõe de aproximadamente 10.000 unidades, predominando as empresas de pequeno porte, das quais $74,6 \%$ têm capacidade instalada menor que $10.000 \mathrm{~m}^{3} /$ ano e $24,7 \%$ entre 10.000 e $30.000 \mathrm{~m}^{3} /$ ano. As empresas de pequeno porte caracterizam-se por apresentar baixo nível tecnológico, mão de obra pouco especializada e dificuldade de estabelecer itens de controle que possibilitem o gerenciamento eficaz do processo produtivo. Considerando a importância socioeconômica e as dificuldades gerenciais e os benefícios que um sistema de medição de desempenho pode trazer para as pequenas e médias empresas, este trabalho teve como objetivo identificar os fatores críticos do processo de produção de esquadrias de madeira em uma empresa de pequeno porte. Para isso, utilizou-se a metodologia análise do modo de falhas e seus efeitos (FMEA), para identificação das falhas potenciais, e a partir delas desenvolver indicadores de desempenho. Foram identificados 24 modos de falha, e todos foram considerados críticos, sendo analisados e monitorados, observando-se que existe potencial de melhoria no processo analisado.
\end{abstract}

Palavras-chave: FMEA, processos e madeira serrada.

\section{SYSTEMIC APPLICATION OF THE FAILURE METHOD EVALUATION ANALYSIS (FMEA) FOR THE DEVELOPMENT OF PERFORMANCE INDICES ON SMALL SIZE ENTERPRISES}

\begin{abstract}
The Brazilian forestry sector employs directly and indirectly 6,5 millions of people. There are, out of these, 2,5 million allocated in the mechanized processed wood sub sector. The industrial park, for the production of sawn wood, has approximately 10.000 units. Most of them are small size enterprises and $74,6 \%$ of them have less than $10.000 \mathrm{~m}^{3}$ year ${ }^{-1}$ of installed capacity. The small size enterprises are present low technology level, workers with poor qualification and difficulties of establishing control items which allow the efficient management of the productive process. Considering their social and economical importance, the managing difficulties of small and medium size enterprises and the use of indices of critical performance in order to improve the management system, this work aims at defining the indices of critical performance of the production process of small size enterprises in wood business. For such, the FMEA methodology was used to identify the potential failures and, as a result, to develop the performance indices. There were 24 types of failure identified, all of them considered as critical. They were analyzed and monitored. It was observed that there is a potential to improve the process.
\end{abstract}

Keywords: FMEA, processes and sawn wood.

\footnotetext{
${ }^{1}$ Recebido em 07.12.2007 e aceito para publicação em 23.06.2009.

${ }^{2}$ Universidade de São Paulo, Escola Superior de Agricultura Luiz de Queiroz. Piracicaba, SP - Brasil. E-mail: <rbmatos@gmail.com> e<macmilan@esalq.usp.br>.
} 


\section{INTRODUÇÃO}

Alguns produtos florestais brasileiros possuem representação crescente e significativa no mercado internacional e compreendem desde a madeira serrada, produzida com baixa tecnologia, a painéis de madeira, produto com tecnologia agregada (NOCE et al., 2003). Para cada milhão de reais investidos na indústria de produtos de madeira, gera-se de 10 a 20 empregos, enquanto nas indústrias automobilística e química esse valor não é suficiente para gerar um posto de trabalho (BNDES, 2003). No início de 2001, a indústria madeireira brasileira apresentou o terceiro maior índice de atividade em relação à capacidade produtiva instalada, em comparação com outros setores da indústria de transformação, o que indica a busca pela consolidação dos mercados e o aumento da produtividade (ABIMCI, 2003).

O segmento de produção de móveis e madeira serrada brasileiro é composto por 13.500 indústrias cadastradas, das quais 10.000 são micro e pequenas empresas e as restantes, de médio e grande portes (BNDES, 2003; ABIMCI, 2003). Apesar do baixo grau tecnológico adotado pelas pequenas e médias empresas desse segmento, o faturamento durante o período de 1999 a 2000 foi de US $\$ 2,93$ bilhões, com um incremento nas vendas de $30 \%$ em relação ao ano de 1998 (BNDES, 2003).

O setor de beneficiamento apresenta excelente perspectiva de conquista de mercados interno e externo, mas necessita desenvolver uma base industrial forte e capaz de produzir em larga escala, visando oferecer produtos competitivos (NOCE et al., 2005; ANGELO et al., 1998). Dessa forma, os métodos gerenciais rotineiramente utilizados em grandes empresas como Toyota, Xerox, GM e HP, entre outras, podem ser aplicados para apoiar a implantação de melhoria contínua dos processos e produtos das empresas de pequeno porte.

Com a inserção do setor florestal no comércio mundial existe a necessidade de fortalecimento dos processos produtivos internos, visando ao crescimento dinâmico e sustentável, impedindo a geração de desequilíbrios nas relações comerciais e financeiras, tão frágeis nas empresas de pequeno e médio portes do setor florestal (ABIMCI, 2003). Nesse ambiente competitivo, torna-se indispensável a utilização de ferramentas de tomada de decisões gerenciais que auxiliem os administradores e acionistas a gerenciar a empresa de forma competitiva, dinâmica e flexível para se adaptar a novos mercados e clientes (PONGELUPPE, 2002). A tomada de decisões dentro da organização deve ser baseada em informações confiáveis e objetivas, utilizando a gestão por fatos e dados. Macedo-Soares e Ratton (1999) destacaram que o objetivo da gestão por fatos e dados não é cobrir toda a extensão do conhecimento sobre um negócio e as contingências que o envolvem, mas possuir a informação que forneça dados para a tomada de decisão eficaz.

Segundo Kaydos (1991), os dados são definidos como coleção de pontos e números, enquanto a informação é o resultado da conversão dos dados de forma que estes possam ser utilizados para a tomada de decisão. Lebas (1995) complementou que os dados geralmente retratam o passado e se tornam informação somente quando são utilizados no processo de tomada de decisão ou são transformados em parâmetros para serem utilizados no processo. O sistema de medição é uma rede que permite monitorar todas as informações geradas em qualquer processo desenvolvido e fornece subsídios para análise do processo em relação a resultados e metas. De acordo com Macedo - Soares e Ratton (1999), os indicadores são definidos como funções que permitem a obtenção de informações sobre medidas relacionadas a um produto, processo, sistema ou uma grandeza ao longo do tempo; quando esses indicadores são organizados em uma construção estruturada, tem-se um sistema de medição.

Segundo Bititci et al. (1997), o sistema de medição de desempenho é responsável por definir como a organização usa as informações geradas nos seus processos. O sistema de informação é considerado o "coração" da medição de desempenho, tendo as funções de fornecer "feedback" e promover o desenvolvimento de ações corretivas para as informações geradas.

Os benefícios da medição de desempenho podem surgir antes que os indicadores gerem as primeiras informações, pois o processo de desenvolvimento promove ampla visão da empresa e do seu ambiente, o que resulta em importante passo para a melhoria do desempenho global do negócio. O ato de medir o desempenho é um processo de negociação de interesses entre os "Stakeholders" (acionistas, empregados, sociedade e clientes) da organização. A análise dos indicadores é importante exercício para identificação de problemas na empresa (KIYAN, 2001). 
O sucesso na utilização das ferramentas gerenciais está diretamente ligado a disponibilidade, acesso, registro, qualidade da informação e envolvimento de todos na organização. O uso da informação para controle e avaliação dos resultados ao final de cada processo, associado à autonomia dada aos funcionários para a tomada de decisão, com base no uso de ferramentas gerenciais, gera agilidade no processo produtivo por meio da solução rápida de problemas e comparação de resultados, podendo modificar ou confirmar os objetivos e os recursos empregados ao longo do processo. Desse modo, as ferramentas gerenciais, aliadas à informação, passam a ser parte integrante do processo de administração estratégica e do processo produtivo (PONGELUPPE, 2002).

Entre as ferramentas gerenciais, destaca-se o método FMEA, desenvolvido em 1949 por militares americanos, com o objetivo de determinar o efeito da ocorrência de falha em sistemas e em equipamentos. A partir de 1988, começou a ser utilizado em empresas como a Chrysler, Ford e General Motors como parte dos chamados programas avançados de planejamento da qualidade em projetos e processos. Segundo Teng e Ho (1996), essa técnica é utilizada na engenharia com a finalidade de encontrar falhas potenciais durante a etapa de projeto, reduzindo, assim, os custos de correções futuras. Xu et al. (2002) destacaram a aplicação do FMEA na redução da probabilidade de ocorrência de falhas e na promoção de melhoria da qualidade de produtos e serviços.

OFMEA é um método analítico, padronizado utilizado para detectar e eliminar problemas potenciais de forma sistemática e completa. Consiste na identificação de todos os possíveis modos potenciais de falha e determina o efeito de cada uma sobre o desempenho de um sistema, seja este um produto, seja um processo. É um método de estudo das causas fundamentais dos problemas de produtos e,ou, processos e tem como principal objetivo identificar e hierarquizar as falhas críticas, apontando o potencial de risco de cada uma e auxiliando a elaboração de um plano de ação para o bloqueio das falhas detectadas (HELMAN e ANDERI, 1995).

Stamatis (1995) destacou que o principal objetivo do método é enfatizar a minimização da probabilidade de ocorrência da falha e de seu efeito e salientou como benefícios de sua utilização: melhoria da qualidade; segurança dos produtos e serviços; melhoria da imagem da empresa e sua competitividade; ajuda a aumentar a satisfação do cliente; reduz custo e tempo de desenvolvimento de produto; auxilia o diagnóstico de processos; e estabelece prioridades para implantação de ações corretivas. Essas ações contribuem para otimização do processo, tornando o produto competitivo no mercado.

Considerando a importância socioeconômica e as dificuldades gerenciais e os benefícios que um sistema de medição de desempenho pode trazer para as pequenas e médias empresas, este trabalho teve como objetivo identificar os fatores críticos do processo de produção de esquadrias de madeira em uma empresa de pequeno porte, aplicando o método FMEA.

\section{MATERIAL E MÉTODOS}

Este trabalho foi desenvolvido em uma empresa familiar de pequeno porte do setor de beneficiamento de madeira serrada para a fabricação de guarnições, forros, rodapés, batentes, portas e esquadrias, localizada no Município de Tietê, SP, com cerca de 30 funcionários. A empresa utiliza-se de madeira de várias espécies, entre elas: cedro (Cedrella spp.), freijó (Cordia goeldiana Huber) e tamarindo (Martiodendron spp.). O sistema produtivo é do tipo sob encomenda, não existindo padronização entre os produtos, modelos e dimensões.

Os indicadores do processo produtivo foram definidos a partir das seguintes etapas: elaboração de fluxogramas do processo, identificação e caracterização do potencial de falha dos pontos críticos e suas causas (FMEA) e estabelecimento dos indicadores de desempenho.

A elaboração dos fluxogramas realizou-se em duas etapas. A primeira referente à construção do fluxograma do macroprocesso, permitindo o entendimento do funcionamento da empresa, desde o desenvolvimento e fabricação do produto até a comercialização. A segunda detalha as etapas do processo produtivo, servindo como base para o desenvolvimento dos indicadores.

A partir da elaboração do fluxograma do processo produtivo, foi feita a identificação dos pontos críticos, utilizando-se o método FMEA para avaliar o potencial de falha no processo produtivo. Realizou-se uma estimativa de ocorrência, severidade e detecção, utilizando-se uma pontuação de 1 a 5, estabelecida na escala Likert, de acordo com Stamatis (1995). A Tabela 1 apresenta os critérios utilizados para determinação dos índices.

R. Árvore, Viçosa-MG, v.33, n.5, p.-977-985, 2009 
Tabela 1 - Critérios utilizados para identificação dos índices de ocorrência, severidade e detecção utilizados no FMEA. Table 1 - FMEA criteria used for the identification of occurrence, severity and detection.

\begin{tabular}{|c|c|c|c|}
\hline \multirow[t]{2}{*}{ Indices } & \multicolumn{3}{|c|}{ Critérios do FMEA } \\
\hline & Ocorrência $(O c)$ & Severidade $(S v)$ & Detecção $(D t)$ \\
\hline 1 & $\begin{array}{l}\text { Probabilidade muito } \\
\text { remota de acontecer }\end{array}$ & $\begin{array}{l}\text { É razoável esperar que o } \\
\text { cliente não perceberá a falha }\end{array}$ & $\begin{array}{l}\text { Probabilidade muito alta } \\
\text { que a falha seja detectada }\end{array}$ \\
\hline 2 & $\begin{array}{l}\text { Número de } \\
\text { ocorrências baixo }\end{array}$ & $\begin{array}{l}\text { O cliente perceberá a falha } \\
\text { mas não ficará insatisfeito } \\
\text { por causa dela }\end{array}$ & $\begin{array}{l}\text { Probabilidade alta de que a } \\
\text { falha seja detectada }\end{array}$ \\
\hline 3 & $\begin{array}{l}\text { Número de } \\
\text { ocorrências moderado }\end{array}$ & $\begin{array}{l}\text { O cliente perceberá a falha e } \\
\text { ficará insatisfeito }\end{array}$ & $\begin{array}{l}\text { Probabilidade média de } \\
\text { que a falha seja detectada }\end{array}$ \\
\hline 4 & $\begin{array}{l}\text { Número de } \\
\text { ocorrências alto }\end{array}$ & $\begin{array}{l}\text { O cliente ficará insatisfeito, } \\
\text { mas não tem sua segurança } \\
\text { afetada }\end{array}$ & $\begin{array}{l}\text { Probabilidade baixa de que } \\
\text { a falha seja detectada }\end{array}$ \\
\hline 5 & $\begin{array}{l}\text { Falhas em proporções } \\
\text { alarmantes }\end{array}$ & $\begin{array}{l}\text { O cliente ficará muito } \\
\text { insatisfeito e afeta a sua } \\
\text { segurança }\end{array}$ & $\begin{array}{l}\text { Probabilidade muito baixa } \\
\text { de que a falha seja } \\
\text { detectada }\end{array}$ \\
\hline
\end{tabular}

Fonte: Stamatis, 1995.

A atribuição dos índices foi realizada pela equipe técnica da empresa com base na Figura 1, sendo o índice de risco (IR) calculado com a equação 1 :

$$
\begin{aligned}
& I R=O c \times S v \times D t \\
& \text { em que: } \\
& I R=\text { índice de risco; } \\
& O c=\text { possibilidade de ocorrência de falha; } \\
& S v=\text { severidade da falha; e } \\
& D t=\text { possibilidade de detecção da falha. }
\end{aligned}
$$

Com base nos resultados, todas as falhas foram estudadas pela equipe técnica da empresa com a aplicação do diagrama de causa e efeito (ou Ishikawa). Para o preenchimento do diagrama, utilizou-se a técnica "brainstorming", do tipo não estruturado, e as prováveis causas foram classificadas utilizando os seis Ms: material, método, mão de obra, máquina, meio ambiente e medidas. A partir da identificação das causas responsáveis por gerar as falhas, foram criados os indicadores de desempenho para o monitoramento.

O desenvolvimento dos indicadores foi contínuo e os resultados, analisados em reuniões periódicas de análise crítica. As reuniões foram realizadas com o objetivo de verificar se os indicadores estavam atendendo às necessidades internas da organização e para assegurar que medidas redundantes e,ou, obsoletas fossem identificadas, revisadas e, ou, descartadas.

\section{RESULTADOS E DISCUSSÃO}

A Figura 1 apresenta o fluxograma do macroprocesso de produção de esquadrias com a interação entre os processos principais e os de apoio. É possível observar a integração entre as etapas que possuem contato direto com o cliente, e essas são consideradas como fundamentais para a fabricação do produto (processos numerados de 7 a 13). É importante destacar que a saída de um processo deve ser considerado como a entrada do próximo: assim, cada etapa possui um cliente externo e outro interno, e o trabalho deve ser realizado de acordo com os requisitos de qualidade propostos por esses clientes. Os processos que executam atividades de suporte (processos numerados de 1 a 6), embora, muitas vezes, não possuam contato direto com o produto e, ou, com o cliente, são responsáveis pelo apoio e indispensáveis para os processos principais.

A Figura 2 apresenta o fluxograma com as etapas e as sequências de atividades do processo produtivo da empresa. A etapa (1) é o processo referente à elaboração do projeto do produto personalizado para o cliente. A etapa (2) corresponde ao recebimento, armazenagem e secagem da matéria-prima. A etapa (3) consiste no pré-corte de batentes (para portas) que compreende as atividades de seleção da madeira, destopo, desengrosso, desempeno, confecção de encaixes e canais de escoamento de água. Na etapa (4), é realizado o pré-corte de caixilho, caracterizado pela seleção da madeira, destopo, desempeno e desengrosso das pranchas. A etapa (5) é o beneficiamento das peças 
Tabela 2 - Índice de risco para os processos produtivos da empresa analisada.

Table 2 - Risk indice for the productive processes of the analyzed enterprise.

\begin{tabular}{|c|c|c|c|c|c|}
\hline \multirow[t]{2}{*}{ Processos } & \multirow[t]{2}{*}{ Pontos Críticos } & \multicolumn{4}{|c|}{ Índices } \\
\hline & & Ocorrência & Severidade & Detecção & $\operatorname{Risco}(I R)$ \\
\hline \multirow{3}{*}{$\begin{array}{l}\text { Secagem e } \\
\text { armazenagem } \\
\text { madeira }\end{array}$} & $\begin{array}{l}\text { Grande quantidade de madeira } \\
\text { descartada }\end{array}$ & 4 & 3 & 3 & 36 \\
\hline & $\begin{array}{l}\text { Madeira exposta ao tempo sem } \\
\text { empilhar }\end{array}$ & 4 & 3 & 3 & 36 \\
\hline & Perda de madeira & 4 & 3 & 4 & 48 \\
\hline \multirow{4}{*}{$\begin{array}{l}\text { Pré corte de } \\
\text { batente e } \\
\text { caixilho }\end{array}$} & Presença de defeitos na madeira & 4 & 3 & 3 & 36 \\
\hline & Retorno de peças com defeitos & 3 & 2 & 4 & 24 \\
\hline & Grande quantidade de sobras & 4 & 4 & 4 & 64 \\
\hline & $\begin{array}{l}\text { Estoque de madeira insuficiente na } \\
\text { fábrica }\end{array}$ & 2 & 3 & 3 & 18 \\
\hline \multirow[t]{4}{*}{ Beneficiamento } & Erros de medida & 3 & 3 & 1 & 9 \\
\hline & Montante fora de esquadro e rachados & 4 & 3 & 3 & 36 \\
\hline & Erros na seleção da madeira & 4 & 3 & 3 & 36 \\
\hline & Atraso de pedidos & 4 & 3 & 1 & 12 \\
\hline \multirow[t]{3}{*}{ Pintura } & Pouco espaço para manuseio de peças & 4 & 3 & 2 & 24 \\
\hline & $\begin{array}{l}\text { Falta de agilidade no processo de } \\
\text { pintura }\end{array}$ & 3 & 4 & 2 & 24 \\
\hline & Elevado consumo de tinta & 4 & 1 & 3 & 12 \\
\hline \multirow[t]{5}{*}{ Montagem } & Peças fora de esquadro & 3 & 3 & 4 & 36 \\
\hline & $\begin{array}{l}\text { Ferragens colocadas em posição } \\
\text { errada }\end{array}$ & 1 & 3 & 1 & 3 \\
\hline & Rachadura em batentes & 3 & 3 & 5 & 45 \\
\hline & Lixamento pouco preciso & 3 & 3 & 4 & 36 \\
\hline & $\begin{array}{l}\text { Peças sem encaixe preciso } \\
\text { (com frestas) }\end{array}$ & 3 & 3 & 4 & 36 \\
\hline \multirow[t]{5}{*}{ Projeto } & Erros de medidas colhidas na obra & 2 & 4 & 3 & 24 \\
\hline & Erros de desenho & 3 & 3 & 4 & 36 \\
\hline & Erros de texto em projeto & 2 & 3 & 3 & 12 \\
\hline & Erro de dimensionamento de peças & 2 & 4 & 2 & 16 \\
\hline & $\begin{array}{l}\text { Erro no cálculo para perfurar peças } \\
\text { em granito }\end{array}$ & 3 & 4 & 5 & 60 \\
\hline
\end{tabular}

Fonte: Elaborada pelos autores.
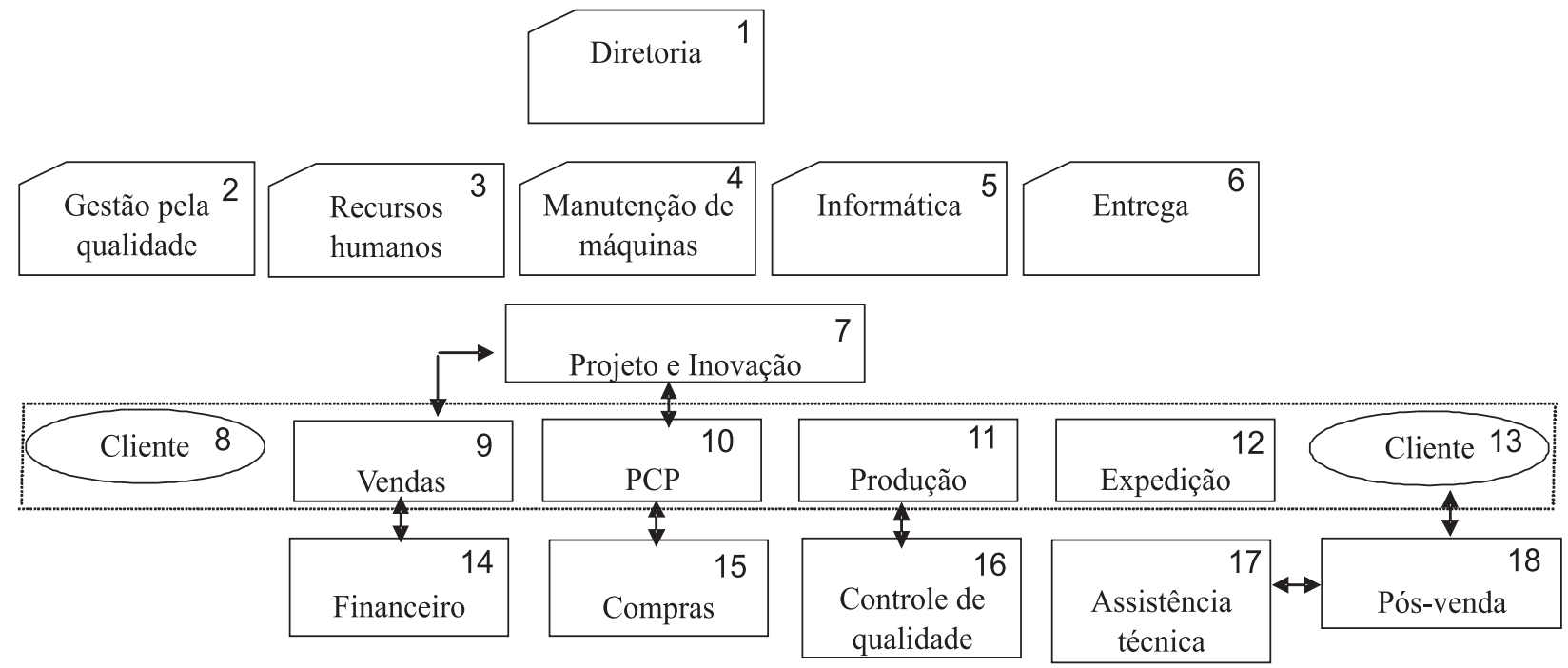

Figura 1 - Macroprocessos da empresa analisada. Fonte: Elaborada pelos autores.

Figure 1 - Macroprocesses of the analyzed enterprise. Source: Elaborated by the authors. 


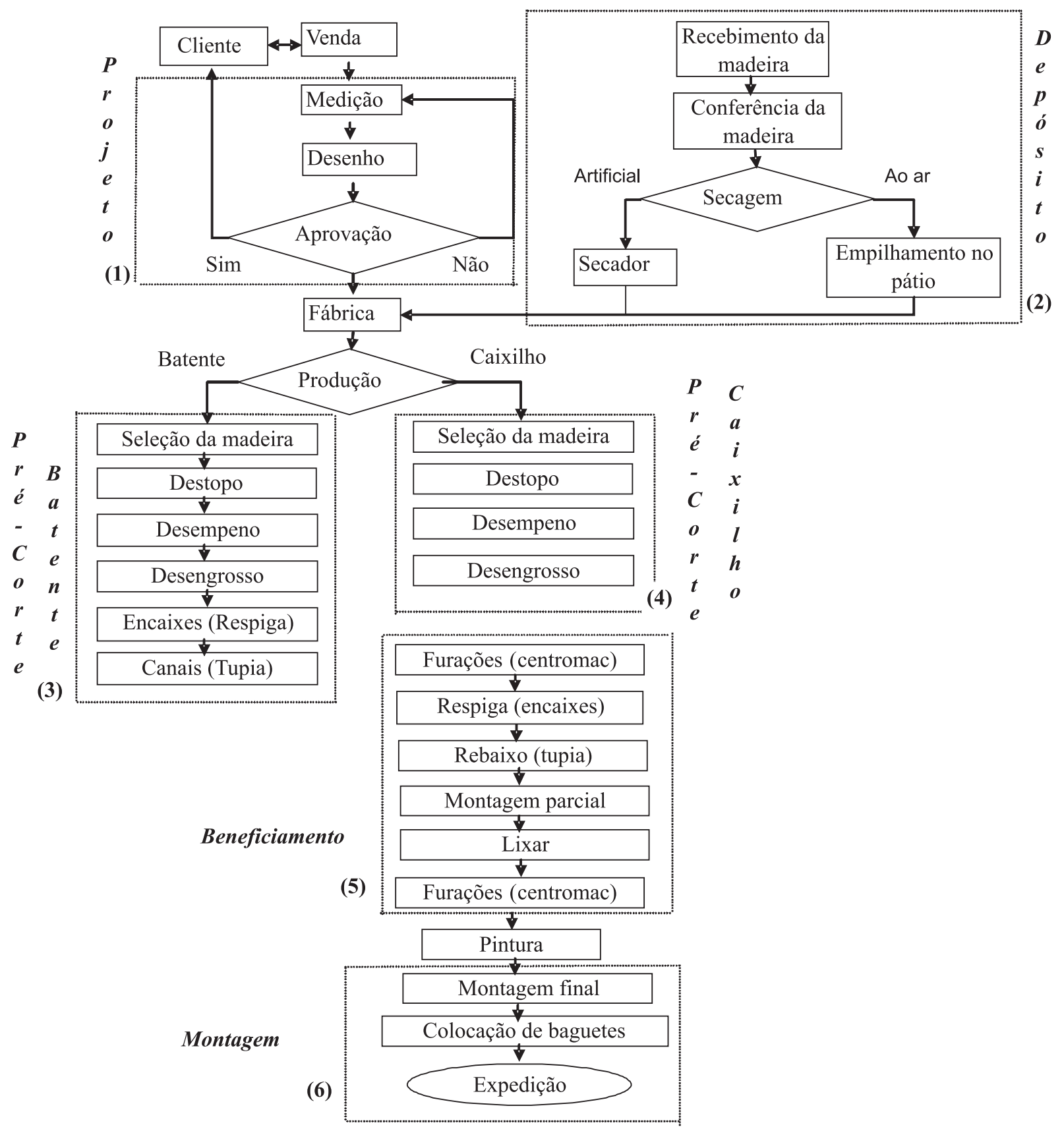

Figura 2 - Etapas do processo produtivo da empresa analisada. Fonte: Elaborada pelos autores.

Figure 2 - Productive process procedure of the analyzed enterprise. Source: Elaborated by the authors.

R. Árvore, Viçosa-MG, v.33, n.5, p.-977-985, 2009 
e inclui as atividades de acabamento (lixamentos e ajustes finos), furação das peças para colocação de ferragens e montagem parcial. A etapa (6) corresponde à montagem final.

Após a estruturação dos processos da empresa em fluxogramas, foram identificados os pontos críticos, por meio da análise do índice de risco. Na Tabela 2, apresentam-se os resultados referentes ao mapeamento de riscos dos processos envolvidos.

De acordo com a Tabela 2, apenas os itens "ferragem colocada em posição errada" (na montagem) e "erros de medida" (no beneficiamento) apresentaram índices de ocorrências com baixo índice de risco, 3 e 9, respectivamente. A Figura 3 apresenta a distribuição de frequências entre as classes dos índices de risco (potenciais de falha) da produção.

Na Figura 3, observa-se que o intervalo de classe 30 - 40 apresenta o maior percentual de falhas que ocorrem no processo. Foram identificados 24 pontos críticos em todo o processo produtivo. Desses foram selecionados, de comum acordo com a equipe, os pontos que obtiveram índice de risco maior que 24 , e, quanto maior o índice de risco, maior o potencial de falha.

Para todos os pontos críticos, desenvolveu-se o diagrama de causa e efeito, identificando-se as principais causas das falhas. A Figura 4 apresenta exemplo do

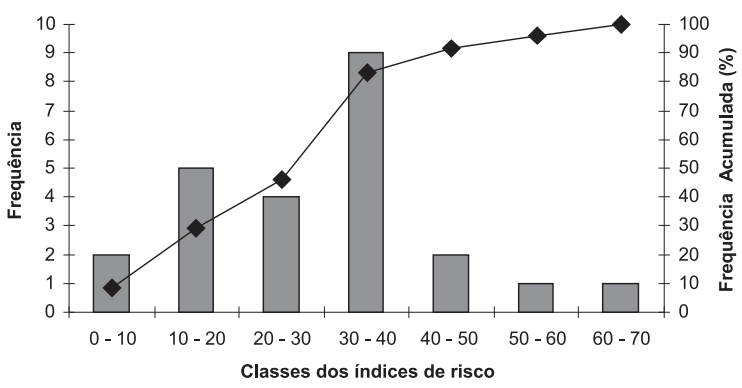

Figura 3 - Índices de risco dos processos críticos da empresa por classes. Fonte: elaborada pelos autores.

Figure 3 - Risk indices of the enterprise critical processes per classes. Source: Elaborated by the authors.

diagrama, referente ao processo de pré-corte de batente e caixilhos, tendo como ponto crítico o retorno de peças com defeito.

$\mathrm{Na}$ Figura 4, podem-se verificar as causas apontadas pela equipe durante o "brainstorming" como agentes causadores da ocorrência das falhas: falta de manutenção das máquinas; falta de treinamento da equipe em metodologia de corte; e baixa qualidade da madeira adquirida.

Para cada causa de falha considerada, como potencial, foi elaborado um indicador de desempenho (Tabela 3) e também montado um cronograma de treinamento para reciclagem da equipe.

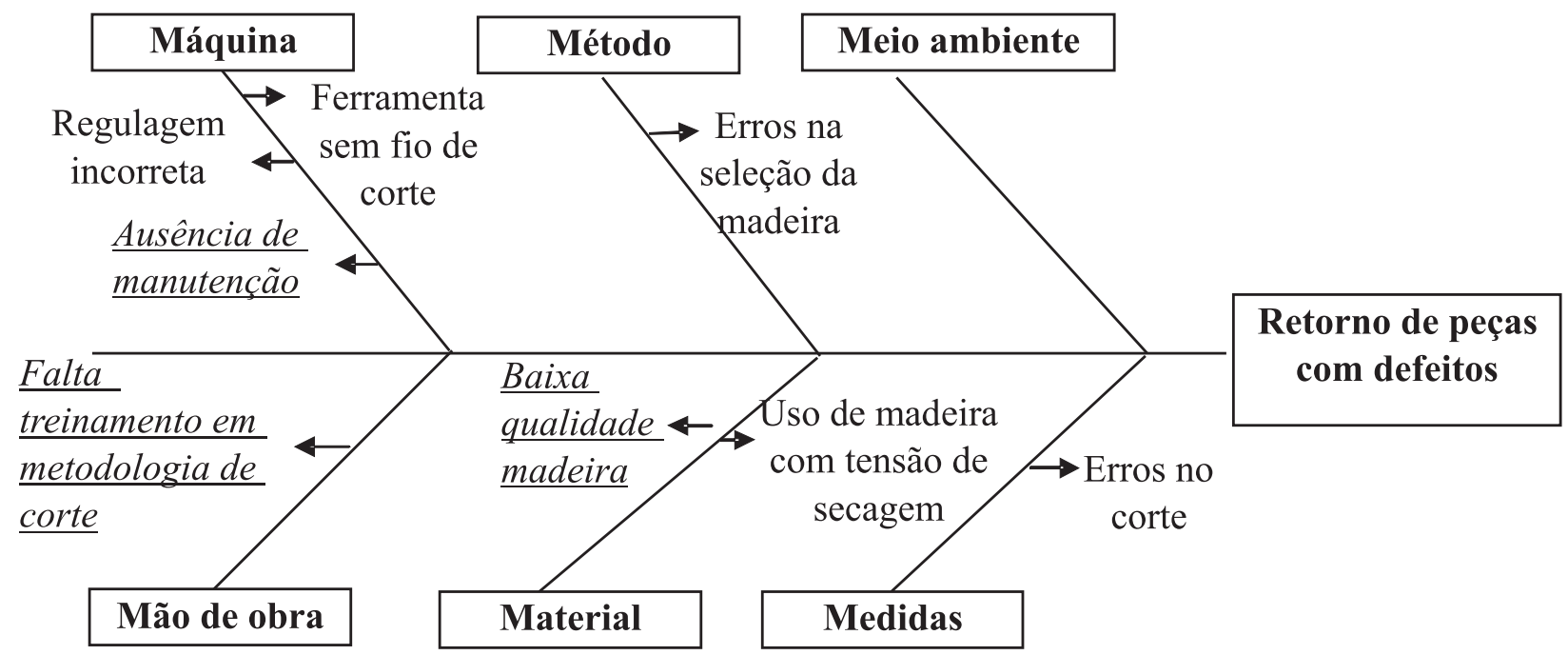

Figura 4-Diagrama de causa e efeito da empresa para retorno de peças com defeitos. Fonte: Elaborada pelos autores. Figure 4- Cause and effect diagram of the enterprise for recurrence parts. Source: Elaborated by the authors. 
Tabela 3 - Indicadores de desempenho para o processo produtivo da empresa analisada.

Table 3 - Performance indicators for the productive process of the analyzed enterprise.

\begin{tabular}{|c|c|c|}
\hline Processos & Indicadores & Unidade \\
\hline \multirow[t]{3}{*}{ Secagem e armazenagem da madeira } & Volume de madeira por espécie em estoque & $\mathrm{m}^{3}$ \\
\hline & Consumo de madeira & $\mathrm{m}^{3} \mathrm{mês}^{-1}$ \\
\hline & Controle de umidade média por secagem & $\%$ \\
\hline \multirow{4}{*}{$\begin{array}{l}\text { Beneficiamento e pré-corte de } \\
\text { batente e caixilho }\end{array}$} & Sobras & $\mathrm{m}^{3}$ \\
\hline & Aproveitamento & $\mathrm{m}^{3}$ \\
\hline & Descarte e razões para descarte de madeira & $\mathrm{m}^{3}$ \\
\hline & Perda de madeira & $\mathrm{m}^{3}$ defeito ${ }^{-1}$ \\
\hline \multirow[t]{2}{*}{ Pintura } & Consumo de tinta e verniz & Litros mês ${ }^{-1}$ \\
\hline & Retrabalho & peças repintadas mês ${ }^{-1}$ \\
\hline \multirow[t]{3}{*}{ Montagem } & Retrabalho & retorno de peças mês ${ }^{-1}$ \\
\hline & Descarte de peças & peças descartadas mês ${ }^{-1}$ \\
\hline & Defeitos no produto & número de defeitos tipo $^{-1}$ \\
\hline \multirow[t]{2}{*}{ Projeto } & Erros de projeto & $\%$ erros mês ${ }^{-1}$ \\
\hline & Retrabalho & número de visitas projeto ${ }^{-1}$ \\
\hline
\end{tabular}

Fonte: Elaborada pelos autores.

Como a empresa em estudo não possuía nenhum tipo de indicador ao longo do processo, foram criados inicialmente indicadores de fácil compreensão e monitoramento pela equipe. O processo de aprimoramento dos indicadores deve ser contínuo e sempre deve ser realizado pela própria equipe por meio da realização de reuniões periódicas de análise crítica. Com base nesses indicadores, é possível implementar o processo de melhoria contínua no processo produtivo.

\section{CONCLUSÃO}

A metodologia mostrou-se de fácil utilização, permitindo identificar no processo analisado 24 pontos críticos, passíveis de monitoração. Com base nesses pontos, desenvolveram-se, inicialmente, 14 indicadores, e os processos com maior número de indicadores foram beneficiamento e pré-corte de caixilho e batente.

\section{AGRADECIMENTOS}

Ao Conselho Nacional de Desenvolvimento Científico e Tecnológico (CNPq), pela bolsa de estudo; e à Martin Esquadrias, pela oportunidade de desenvolver este trabalho.

\section{REFERÊNCIAS}

ANGELO, H.; HOSOKAWA, T. R.; BERGER, R. O Brasil no mercado internacional de madeiras tropicais. Revista Árvore, v.22, n.4, p.483494, 1998.

R. Árvore, Viçosa-MG, v.33, n.5, p.-977-985, 2009
ASSOCIAÇÃO BRASILEIRA DA INDÚSTRIA DE MADEIRA PROCESSADA MECANICAMENTE ABIMCI. Madeira processada

mecanicamente: estudo setorial 2001. 32p.

BANCO NACIONALDE DESENVOLVIMENTO ECONÔMICO E SOCIAL - BNDES. 2003. Micro, pequenas e médias empresas. Disponível em: <http://www.bndes.gov.br/pme/default.asp> Acessado em: 31de jan. de 2003.

BITITCI, U. M.; CARRIE, A. S.; McDEVITT, L. Integrated performance measurement systems: an audit and development guide. The TQM

Magazine, v.9, n.1, p.46-53, 1997.

HELMAN, H.; ANDERY, P. R. P. Análise de falhas: aplicação dos métodos de FMEA e FTA. Belo Horizonte: Fundação Christino Ottoni, 1995. $156 \mathrm{p}$.

KAYDOS, W. Performance measurement and performance management. Measuring, manaing and maximizing performance. Portland: Productivity Press, 1991. p.33-51.

KIYAN, F. M. Proposta para desenvolvimento de indicadores de desempenho como suporte estratégico. 2001. 108f. Dissertação (Mestrado em...) - Escola de Engenharia de São Carlos, Universidade de São Paulo, 2001. 
LEBAS, M. J. Performance measurement and performance management. International Journal of Production Economics, n. 41, p.23-35, 1995.

MACEDO-SOARES, T. D. L. V. A.; RATTON, C. A. Medição de desempenho e estratégias orientadas para o cliente: resultados de uma pesquisa de empresas líderes no Brasil. Revista de Administração de Empresas, v.39, n.4, p.46-59, 1999.

NOCE, R. et al.. Desempenho do Brasil nas exportações de madeira serrada. Revista Árvore, v.27, n.5, p.695-700, 2003.

NOCE, R. et al. Análise de risco e retorno do setor florestal: produtos da madeira. Revista Árvore, v.29, n.1, p.77-84, 2005.
PONGELUPPE, P. C. Modelo de indicadores de desempenho para micro e pequena agroindústria: multi-caso de laticínios. 2002. 169p. Dissertação (Mestrado em...) Universidade Federal de São Carlos, São Carlos, 2002.

STAMATIS, D. H. Failure mode and effect analysis: FMEA from theory to execution. Wisconsin: ASQ Quality Press, 1995. 494p.

TENG, S. H. G.; HO, S. Y. M. Failure mode and effect analysis: an integrated approach for product design and process control. International Journal of Quality \& Reliability Management, v.13, n.5, p.8-26, 1996.

XU, K. et al. Fuzzy assessment of FMEA for engine systems. Reliability Engineering and System Safety, n.75, p.17-29, 2002. 